\title{
Getting it Right: Estimating the Share of Volunteers in Denmark
}

\author{
Jonathan Hermansen \\ Department of Research and Development \\ University College UCC, Denmark \\ Email:JOHE@ucc.dk
}

\begin{abstract}
Abraham, Helms and Presser (2009) demonstrated that people who volunteer are more likely to participate in surveys. The apparent consequence of such a pattern among respondents is that estimates of volunteering could be biased. Surveys with voluntary work as the main topic could be further biased due to the volunteers' interest on this issue compared with non-volunteers. The article uses panel data from Denmark in order to examine the bias due to panel attrition as a special kind of nonresponse bias and its consequences for estimates of volunteering. The results show that panel attrition leads to an overestimation of the share of people who volunteer.
\end{abstract}

Keywords: Volunteering, panel attrition, participation, social desirability

\section{Introduction}

Panel attrition in longitudinal studies can give biased estimates (Callegaro \& DiSogra, 2008), which is why many researchers are exploring a wide variety of incentives and attributes to encourage more people to participate in surveys (Keeter, Miller, Kohut, Groves, \& Presser, 2000; Ryu, Couper, \& Marans, 2006; van Ingen, Stoop, \& Breedveld, 2009). Panel attrition may introduce bias if it is not random, and it is particularly troubling if the nonresponse pattern is somehow related to the outcome of one or more of the key variables of interest (see also Hauser, 2005). This article investigates how volunteering affects the potential respondents' willingness to participate in surveys on volunteering in the case of Denmark, but the results are likely to reflect the same obstacles in many other European countries that depend on survey estimates, particularly those that rely on longitudinal studies.

Abraham, Helms and Presser's (2009) study demonstrated that nonresponse did inflict bias on estimates of volunteer work in the United States since the probability of participation in a survey is associated with doing volunteer work. The reason that survey participation and volunteering might coincide could be that they express a similar set of personal traits. Both activities are characterized by a willingness to devote time to something that may not offer immediate benefits to the participant. It has been argued that survey 
participation is closely linked with the notion of civic duty (Groves, Singer, \& Corning, 2000).

A panel attrition bias on estimates of volunteering would imply that other measures of prosocial activities could be overestimated due to a social desirability bias (Cnaan, Jones, Dickin, \& Salomon, 2011). That is, people would be more interested in participating in surveys that would allow them to tell about their social engagements if they are engaged in such activities. The outcome would be that nonresponse would lead to overestimations of prosocial activities in general.

The article is organized in the following way. First, a review of the literature on survey participation and potential barriers that lead to nonresponse or panel attrition is discussed. Survey participation is associated with a demonstration of civic duty, which is a reason to test whether panel attrition affects estimates of volunteering and the degree to which survey participation and volunteering are associated. Second, the research question, which concerns how volunteering may affect survey participation in a panel on volunteering and how panel attrition in return could distort the estimates of volunteering in Denmark, is discussed. Third, the design and the results of the analysis are shown; employing data from a two-wave panel survey allowed an analysis of the extent to which the attrition can be ascribed to whether or not the respondents volunteer. Finally, the effect of panel attrition on estimates of volunteering is summarized, and the consequences for measures of volunteering and prosocial activities are elaborated.

\section{Previous Research}

The key dependent variable of this study concerns the decision of whether or not to participate in the second wave of the survey. In other words, the primary aim is to identify the factors that cause panel attrition. Panel attrition may be treated as a type of nonresponse since the effect of panel attrition is a lower overall response rate. In a longitudinal survey, as used in this study, attrition is defined as the percentage of members in the panel who drop out from one wave to the next.

The decision not to take part in a survey may be determined by the characteristics of the individual respondent (e.g., the gender of the respondent) or the design of the questionnaire (e.g., the number of questions or the personalization of the cover letter). Respondent factors have been shown to be more influential than survey design factors in determining what causes panel attrition and nonresponse in general (Helgeson, Voss, \& Terpening, 2002). In this article, attention is directed towards three categories of respondent factors that may contribute to panel attrition. First is a lack of interest in the topic of the survey (Groves et al., 2000). Second is the absence of a prosocial attitude and the sense that it is important to participate in non-commercial population surveys (Sharp \& Frankel, 1983). Third is a general lack of knowledge or aptitude to answer and understand the questions of the interview (Tourangeau, 2003). The following section describes how these three factors may affect the decision to participate in a survey.

In survey research, it has been well-established that a respondent's interest in the topic is a crucial factor impacting the decision to participate in surveys (Heberlein \& Baumgartner, 1978; Sheehan \& McMillan, 1999). The importance of the survey topic is referred to as 'topic saliency' within the survey research literature (e.g., Zillmann, Schmitz, Skopek, and Blossfeld, 2014). However, 
respondents may also be motivated by the interviewer and a number of other contextual factors (Campanelli \& O'Muircheartaigh, 1999). Hence, it has been proposed that the decision to participate in surveys could be perceived as a form of community involvement (Couper, Singer, \& Kulka, 1998). This would help to explain why certain subpopulations are typically more inclined to participate in surveys when being invited.

Evidence suggests that the sense of civic duty in filling out a questionnaire is a better indicator of survey participation than the amount of time that people have on their hands (Pääkkönen, 1998). Voogt and Saris (2003) demonstrate that the sense of civic duty, along with an attachment to the local community, is likely to increase the probability of participating in surveys. Thus, people who volunteer are more likely to express a higher degree of civic duty, as they would have an inherent interest in the topic of volunteering. This argument would support the notion that volunteer work and survey participation are associated. If prosocial attitudes are crucial for survey participation, it could imply profound bias on estimates of civic engagement, such as volunteering, without a compensatory research design. Moreover, social desirability could explain the coinciding of volunteering, survey participation and the awareness of civic duties. It could lead to overestimation of civic engagement, and the overestimation would increase as response rates decrease (Wilson, 2012).

Abraham, Maitland and Bianchi (2006) demonstrate that the use of weights will improve measures of volunteering along with measures of daily activities, such as household chores, albeit with a modest effect. Such weights could take into account the demographic characteristics of the respondents when compared with non-respondents or with the entire population of interest. It should be noted that gender has been identified as a relevant factor in studies of panel attrition, as men tend to attrite more frequently than women do (Uhrig, 2008). This finding is congruent with previous studies of nonresponse differences between men and women (e.g., Sax, Gilmartin, \& Bryant, 2003).

Another reason for panel attrition could be the inability to comprehend and answer questions in the survey. A bias could arise if incomprehension is related to the propensity to answer the questions of the survey. In this context, incomprehension as a barrier does not refer to intelligence but only to the capability and self-confidence necessary to accept the request and complete a survey interview. Thus, one reason an individual would not participate in a survey is communication difficulties (Johnson, O'Rourke, Burris, \& Owens, 2002). This could partly explain why people with more resources, such as educational achievements and sufficient comprehension, are more likely both to volunteer and to participate in surveys (e.g., Abraham, Helms, and Presser, 2009; Freese, 2006; Wilson, 2000).

\section{The Research Question}

Abraham et al. (2009) note that low response rates may have contributed to higher estimates of the volunteering rate. In other words, the nonresponse bias may skew the estimates of volunteering positively. Volunteer work is associated with possession of resources and social networks (see Wilson, 2012; Wilson \& Musick, 1997), which would make the implication of the bias even stronger. It could also imply that other activities reflecting a prosocial attitude and possession of personal resources would be overestimated as well.

Therefore, it seems plausible to assume that volunteer work and survey participation are associated. Volunteering is also associated with a possession 
of personal resources and skills. Thus, panel attrition due to communication difficulties could lead to an overestimation of the share of people who do voluntary work. Panel attrition could also lead to an underestimation of the importance of the association between incomprehension and volunteering, due to the self-selection in the panel, which may affect the representativeness of those with a lower aptitude.

Based on previous studies of survey participation and volunteering, the research question of this article is formulated as follows: How does volunteering affect panel attrition in surveys concerned with voluntary work?

The question derives from the study of Abraham et al. (2009). This article attempts to test the association between volunteering and panel attrition within a European country, namely Denmark. If there were an association to be found, it would imply that estimates of volunteering would be skewed. Thus, this article aims at identifying the importance of such a distortion on estimates of volunteering.

\section{Data and Variables}

Zillmann et al. (2014) identified two common approaches to examining how respondents' interest in the topic affects the survey estimates. One approach is to conduct a classical experimental study with a treatment group and a control group in randomized trials. The stimuli could be different presentations or content of survey items in a controlled environment. These experiments have the obvious advantage of avoiding selection bias. However, one should be cautious when drawing conclusions because of the varying external validity of such experiments (Barabas \& Jerit, 2010).

A different approach is to use panel data. Panel data enable researchers to determine issues of order since all the data is collected at different times. Hence, it is possible to track changes in the same respondents over time. The drawback of this approach is that it is difficult to determine the causal impact of each stimulus that might affect the decision to participate.

This study uses panel data to investigate the potential bias. It is based on data from a Danish two-wave population survey. The surveys were carried out in 2004 and 2012 with an identical focus on volunteering, charitable giving and informal helping in Denmark. The principal aim of the surveys was to map the extent of these activities in Denmark and to track potential changes over the years. The surveys functioned as the empirical foundation of a large-scale research collaboration concerning the composition of civil society in Denmark. The Danish National Centre for Social Research collected the responses. The questionnaires were developed in cooperation with researchers from Aalborg University, Roskilde University and the University of Southern Denmark. The 2004 survey was designed to be representative of the adult Danish population with a simple random sampling of respondents. The survey in 2012 was designed as a panel study, which included all the respondents from the previous survey who were younger than 86 years of age. In addition, a supplementary sample was conducted to ensure a sufficient number of respondents. The sampling frames were created using administrative records, which provide an exhaustive coverage of the Danish population. The response rates in each of the two surveys were $75 \%$ (first wave) and $71 \%$ (second wave). Hence, the overall response rate of the panel study, from the initial survey through the second survey, was $53 \%$. The response rate of the supplementary sample collected in 2012 was 59\% (Fridberg, 2014c). In both surveys, most of the 
interviews were conducted over the telephone. In the case of non-contact, interviewers were sent out in person. The analysis is based on the answers of 2,511 respondents from the 2004 survey. The empirical model contains respondent factors, two demographic control variables and a dependent variable.

Table 1 - Descriptive Statistics of the Dependent and Independent Variables

\begin{tabular}{lcrrrr}
\hline \multicolumn{1}{c}{ Variable } & $\mathbf{n}$ & Mean & Std. Dev. & Min & Max \\
\hline Attrition & 2511 & 0.331 & 0.471 & 0 & 1 \\
\hline Volunteer & 2511 & 0.368 & 0.483 & 0 & 1 \\
\hline Incomprehension & 2511 & 0.096 & 0.295 & 0 & 1 \\
\hline Years of School & 2511 & 10.435 & 2.116 & 6 & 15 \\
\hline Trust in Associations & 2511 & 0.831 & 0.375 & 0 & 1 \\
\hline Obligation & 2511 & 1.330 & 0.897 & 0 & 2 \\
\hline Pol. Interest & 2511 & 1.714 & 0.842 & 0 & 3 \\
\hline Male & 2511 & 0.483 & 0.500 & 0 & 1 \\
\hline Age & 2511 & 45.023 & 14.816 & 16 & 76 \\
\hline
\end{tabular}

The dependent variable of this study is panel attrition. It is a simple dichotomous variable that represents whether the respondent who participated in the 2004 survey took part in the subsequent wave in 2012. Unfortunately, even if contact was established, any reasons that the respondents may have given for refusing to participate in 2012 are not matched with the individual respondent. Therefore, the analysis consists of respondent factors from the 2004 survey.

First, the primary independent variable is whether the respondents were volunteering in 2004. The respondents were asked if they had volunteered within the last 12 months. In total, $36.8 \%$ of the respondents reported they had been actively engaged in voluntary work within the last 12 months. Above, Table 1 states that the attrition rate is $33 \%$, so approximately $67 \%$ of the 2004 respondents also participated in 2012. The attrition rate is 4 percentage points higher than would be expected if the focus was on the overall response rate of the second wave in the panel study. This is due to the listwise deletion of respondents who did not answer all of the interview questions. That is, the $67 \%$ completion rate contains only those respondents who completed the entire interview. The a priori selection-in the sense that only people who participated in 2004 were eligible for the panel-has to be considered in order to determine whether the completion rate is satisfying (see also Schoeni, Stafford, Mcgonagle, \& Andreski, 2013). In total, $19.6 \%$ refused to take part in the second wave, whereas the remaining non-respondents were either ill, could not be found or had moved to an unknown address (Fridberg, 2014a). It is not possible, due to data limitations, to distinguish between different sources of attrition in the analysis.

Second, a set of variables measured the prosocial attitude of the respondents. One question asked the respondents if they felt morally obligated to donate money to charity. The answers were coded into three categories: 'agree', 
'neither agree nor disagree' and 'disagree'. Since the three categories were given the values of zero, one, and two, respectively, the mean value of 1.3 shows that more people disagreed than agreed with the statement regarding moral obligations (see Table 1). Another item asked if the respondent had trust in voluntary associations. The variable was a dummy variable indicating whether the respondent trusted voluntary associations or had little/no trust in voluntary associations. Table 1 shows that $83 \%$ of the respondents trusted voluntary associations. The final variable concerning the prosocial attitude of the respondents asked how interested the respondent was in politics. The question consisted of a four-point rating scale, from 'no interest' (assigned the value zero) to 'very interested' (assigned the value three). As shown in Table 1, the average score of political interest was 1.7.

Third, two variables measured the respondents' comprehension and personal resources. One dummy variable measured whether the respondent had difficulties understanding the questions during the interview. Unlike the other variables, this question is the judgment of the interviewer immediately after the interview. In total, $9.6 \%$ of the respondents were reported to have had difficulties answering the question. The other variable measured the years of school completed by the respondent. On average, the respondents had completed 10.4 years of school. The variable did not distinguish between any educational achievements of upper-secondary level. However, in terms of understanding the questions during the interview, there is little reason to believe that there would be significant differences among people who had finished 15 years of school.

The demographic control variables were gender and age. Table 1 shows that $48.3 \%$ of the sample were men, the average age was 45 years and the respondents' ages ranged from 16 to 76 years (in 2004).

\section{Analysis}

Fridberg (2014b) mapped the field of volunteers in Denmark. He concluded that the share of men who volunteer is slightly higher than for women and that people aged 36 to 45 are the most likely to volunteer across all age groups. In addition, a larger share of people with higher education do volunteer work as compared to people with little or no education (Fridberg, 2014b, p. 52). Furthermore, Qvist (2014, p. 181) argued that language barriers are one of the key reasons immigrants are less engaged in voluntary work as compared to the rest of the population. Overall, the level of volunteering in Denmark has been relatively stable in recent years (Fridberg, 2014c).

A logistic regression model is used to determine how the respondent factors contribute to panel attrition. The results of the logistic regression models are presented in Table 2. The table contains the regression coefficients (log odds) represented, as well as the robust standard errors. In the model, the value of the squared age variable is included to allow for a nonlinear association. Furthermore, Table 2 contains a column of the percentage change in the odds of panel attrition for a unit increase in each of the independent variables. The interpretations of the coefficients and the percentage change should take into consideration the statistical significance denoted by asterisks. In order to investigate whether the model is specified correctly, a formal test was conducted that entailed testing whether a squared term of the predictors was significant. The test yielded a $p$-value of .41 . Hence, this test did not show any problems or misspecifications with the model. 
Table 2 - Logistic Regression of Panel Attrition

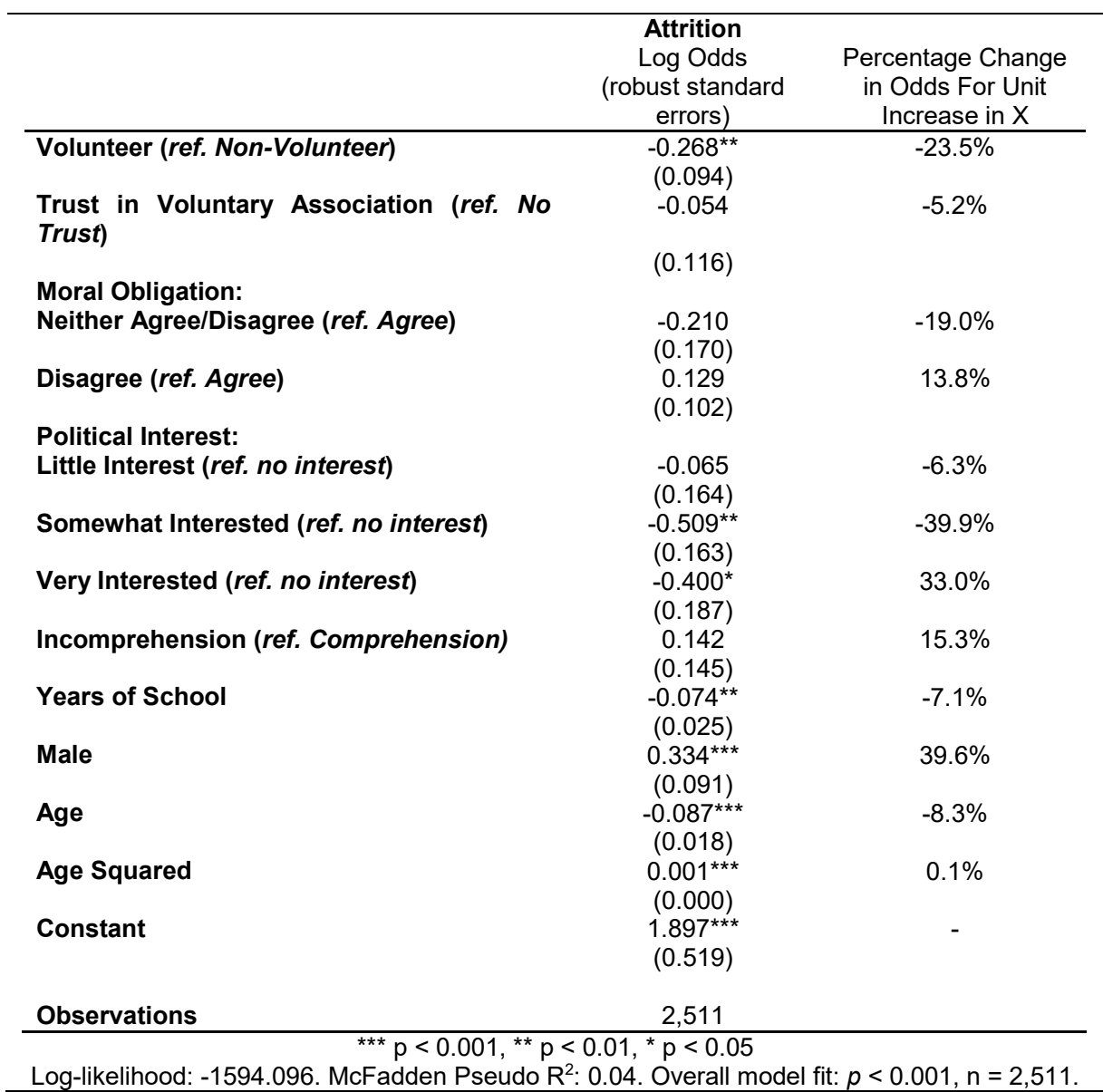

Table 2 shows the results of the logistic regression model. Most importantly, the results confirm that volunteering is negatively associated with panel attrition. The association is statistically significant $(p<0.01)$. Volunteering in 2004 decreased the odds of opting out of the survey in 2012 by $23.5 \%$. This finding suggests that there is reason to believe that estimates of volunteering could also be skewed in Denmark due to attrition rates. In other words, people who volunteer are more likely to take part in surveys on voluntary work.

Concerning the prosocial attitude of the respondents, the results indicate that these measures may have less impact on panel attrition. Neither the trust expressed in voluntary associations nor the question of donations to charity as a moral obligation is statistically significant. A higher interest in politics decreases the likelihood of dropping out of the panel. Respondents who said that they were 'somewhat' or 'very' interested in politics had a $39.9 \%$ and $33.0 \%$ chance of lower odds of attrition, respective to the years of the study, as compared with those who had 'no' interest in politics.

The results of the variables that measure the comprehension and personal resources for survey participation show that years of school is a significant predictor of the attrition rate $(p<0.01)$. Each additional year of education reduces the odds of attrition by $7.1 \%$. On the other hand, difficulties understanding the questions (e.g., due to language problems) is not a significant predictor. This finding could in part be explained by the fact that the model controls for years of school, and that a relatively small group of respondents 
were reported as having problems understanding the interview questions. Furthermore, it is possible that some people who would find it difficult to complete an interview had opted not to participate in the first survey of 2004. Hence, they would not have been invited for the second survey in 2012.

Both of the demographic control variables are significant. In accordance with the results of Lugtig's (2014) study, men are less likely to remain a part of the survey. Furthermore, middle-aged people, who are also more likely to carry out voluntary work in Denmark (Fridberg, 2014b), have a higher propensity to participate in the survey. The attrition rate is significantly higher among men as compared with women $(p<0.001)$. Men have $39.6 \%$ higher odds of dropping out of the panel. The age variable is included in simple form and as a squared term. The negative coefficient of age and the positive coefficient of age squared show that the attrition rate is highest among the youngest and the oldest. Thus, panel attrition in relation to age has a u-shape, and the association between attrition and age is significant $(p<0.001)$.

Figure 1 illustrates how volunteering affects the probability of panel attrition. As the regression analysis shows, other factors contribute to panel attrition as well. Hence, the figure shows how the attrition rate differs between men and women depending on years of education ( $95 \%$ confidence intervals have been added to display the statistical uncertainty). The estimates of Figure 1 contain the same independent variables as the regression analysis.

Figure 1 - Predicted Probabilities of Panel Attrition for Women and Men on a Scale of Years of School

Figure 1 - Predicted Probabilities of Panel Attrition for Women and Men on a Scale of Years of School

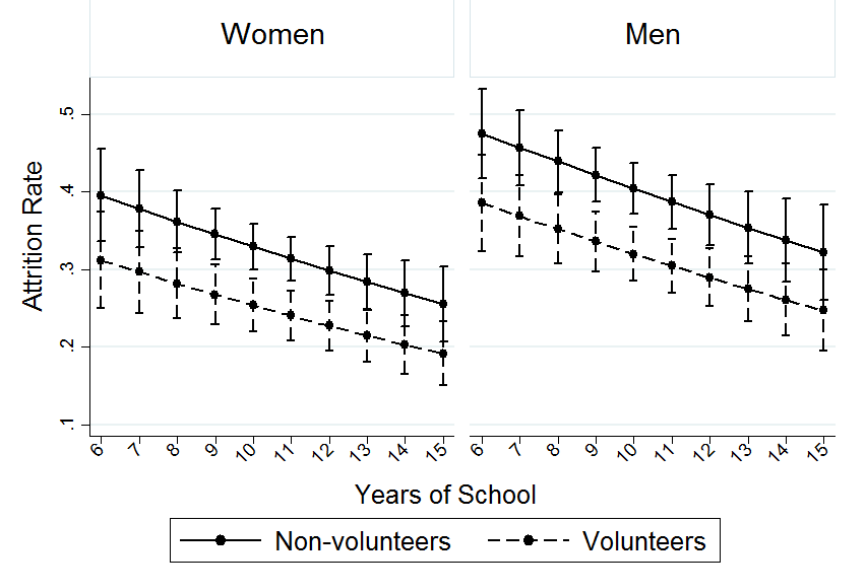

Figure 1 shows the discrepancy between volunteers and non-volunteers in terms of panel attrition. Volunteers are more likely to participate in the second wave as compared with non-volunteers. Moreover, Figure 1 illustrates that the differences can be substantial. Women and people with more years of education have lower attrition rates. In order to assess the question of how panel attrition then affects estimates of volunteering, it is useful to look at the overall probability of panel attrition for the volunteers and non-volunteers, respectively. The overall probability of panel attrition is $29.5 \%$ for a volunteer and $35.1 \%$ for a non- 
volunteer when controlling for the other independent variables, resulting in a 5.6 percentage points difference that is statistically significant $(p=0.004)$.

The nonresponse bias due to panel attrition could increase in every subsequent wave, thus leading to a much greater bias. The topic saliency could amplify panel attrition, as the respondents would be familiar with the questions from the previous wave. Thus, the experiences from the first survey could affect the decision to participate in subsequent surveys, although there are many other possible influences on whether one participates. It is not possible to determine to what extent this effect is at play in this study. However, the eight-year gap between the two waves is likely to reduce the individual respondent's recollection of the previous interview.

It would be necessary to continue the panel design in future waves of the population survey on volunteering in order to examine whether panel attrition amplifies the non-response bias due to non-volunteers opting out. However, a simple way to estimate the potential bias due to panel attrition is to compare the rate of volunteers in the 2012 panel to that of the supplementary sample collected in the same year. In the panel, 39\% reported volunteering within the last year, whereas the corresponding statistic is $29 \%$ in the supplementary sample. This suggests that panel attrition is likely to bias the overall estimate. If one relies on the panel data without considering panel attrition, the share of volunteers appears to be overestimated. As the results of this study indicate, if one estimates the overall rate of volunteers, controlling for demographic characteristics, the bias could be reduced. It is unlikely that it could remove the bias entirely, as the attrition is contingent on factors that are difficult to measure. For instance, whether or not the respondent was volunteering in the previous wave is not an exhaustive indicator of topic saliency. The nonresponse bias from panel attrition may very well differ from other sources of nonresponse (e.g., the nonresponse obtained during the first wave). It seems plausible to assume the share of volunteers among those refusing in the first wave would be lower when compared with the respondents of the survey, as was the case when comparing the 2012 panel study and the supplementary sample. Therefore, the nonresponse bias discussed in this analysis is only a partial investigation of the overall nonresponse bias. Both the bias related to the topic saliency and the decision to respond prior to the first survey in 2004 are worth considering, especially since many researchers in recent decades have faced problems with decreasing response rates (Peytchev, 2013). The lower response rate in the supplementary survey from 2012 as compared with the 2004 survey serves as an example of this trend. Thus, an exclusive focus on panel attrition as a source of bias is likely to overlook many aspects that could affect the aggregated estimates of volunteering rates.

\section{Summary and Implications}

Panel attrition is a specific kind of nonresponse in the sense that people have already participated in a previous survey on the same topic. Therefore, the most reluctant people may have declined an invitation during the first wave of the survey. The problems related to panel attrition are nevertheless analogous to challenges of other sources of nonresponse. It creates a bias if the nonresponse is in some way related to the key variables of the study.

The research question of this article concerns how volunteering affects panel attrition. The results show that people who volunteer are more likely than nonvolunteers to remain in the panel. The difference is statistically significant, and this finding is in accordance with the study by Abraham et al. (2009). 
Furthermore, the propensity to participate in the survey is affected by political interest, which indicates the need to account for more than demographic variables when identifying nonresponse bias.

The findings of the analysis reveal that the estimates of volunteering in Denmark are likely to be biased. It appears that panel attrition leads to an overestimation of the volunteering rate. The bias due to panel attrition may only in part be accounted for by controlling for demographic characteristics (e.g., education and gender). The findings of this article are consistent with similar empirical studies, which gives reason to believe that the nonresponse bias on estimates of volunteering could be found in other European countries as well. Furthermore, the measure of volunteering is closely linked with measures of other prosocial activities and civic engagement in general.

A study conducted by Groves, Presser and Dipko (2004) demonstrates how topic interest affects survey participation in studies that cover diverse areas, such as education, childcare and voting. Their study showed that the odds of cooperating are approximately $40 \%$ higher for topics of likely interest than for other topics (Groves et al., 2004, p. 25). These results indicate that any survey with a topic that is more salient for a specific subpopulation (e.g., volunteers) is likely to suffer from similar problems concerning nonresponse bias, which would then have an impact on estimates of prosocial activities or attitudes. The bias would, in most cases, lead to an overestimation of the share of people who are engaged in prosocial activities, as they would have greater interest in the topic and, hence, be more likely to participate in surveys regarding such matters. Therefore, nonresponse bias due to panel attrition is likely to affect estimates of related prosocial activities, in addition to voluntary work. This article demonstrates that the tendency among non-volunteers to opt-out could be amplified in subsequent waves of a panel study, which would worsen the initial nonresponse bias in surveys concerning volunteering.

\section{References}

Abraham, K. G., Helms, S., \& Presser, S. (2009). How social processes distort measurement: The impact of survey nonresponse on estimates of volunteer work in the United States. American Journal of Sociology, 114(4), 1129-1165. https://doi.org/10.1086/595945

Abraham, K. G., Maitland, A., \& Bianchi, S. M. (2006). Nonresponse in the American time use survey: Who is missing from the data and how much does it matter? Public Opinion Quarterly, 70(5), 676-703. https://doi.org/10.1093/poq/nfl037

Barabas, J., \& Jerit, J. (2010). Are survey experiments externally valid? American Political Science Review, 226-242. https://doi.org/10.1017/S0003055410000092

Callegaro, M., \& DiSogra, C. (2008). Computing response metrics for online panels. Public Opinion Quarterly, 72(5), 1008-1032. https://doi.org/10.1093/poq/nfn065

Campanelli, P., \& O'Muircheartaigh, C. (1999). Interviewers, interviewer continuity, and panel survey nonresponse. Quality and Quantity, 33(1), 59-76. https://doi.org/10.1023/A:1004357711258

Cnaan, R. A., Jones, K. H., Dickin, A., \& Salomon, M. (2011). Estimating giving and volunteering: New ways to measure the phenomena. Nonprofit and Voluntary Sector Quarterly, 40(3), 497-525. https://doi.org/10.1177/0899764010365741 
Couper, M. P., Singer, E., \& Kulka, R. A. (1998). Participation in the 1990 decennial census: Politics, privacy, pressures. American Politics Research, 26(1), 59-80. https://doi.org/10.1177/1532673X9802600104

Freese, J. (2006). Cognitive skills and survey nonresponse evidence from two longitudinal studies. CDE Working Papers (No. 2006-10). Madison, WI.: University of Wisconsin-Madison.

Fridberg, T. (2014a). Hvem er de frivillige? In L. S. Henriksen \& T. Fridberg (Eds.), Udviklingen i frivilligt arbejde 2004-2012 (Vol. 14:09, pp. 47-68). Copenhagen: SFI.

Fridberg, T. (2014b). Udviklingen i frivilligt arbejde 2004-2012. In L. S. Henriksen \& T. Fridberg (Eds.), Udviklingen i frivilligt arbejde 2004-2012 (Vol. 14:09, pp. 29-46). Copenhagen: SFI.

Fridberg, T. (2014c). Design, Metode og Data. In L. S. Henriksen \& T. Fridberg (Eds.), Udviklingen i frivilligt arbejde 2004-2012 (Vol. 14:09, pp. 23-28). Copenhagen: SFI.

Groves, R. M., Presser, S., \& Dipko, S. (2004). The role of topic interest in survey participation decisions. Public Opinion Quarterly, 68(1), 2-31. https://doi.org/10.1093/poq/nfh002

Groves, R. M., Singer, E., \& Corning, A. (2000). Leverage-saliency theory of survey participation. Public Opinion Quarterly, 64(3), 299-308. https://doi.org/10.1086/317990

Hauser, R. M. (2005). Survey response in the long run: The Wisconsin longitudinal study. Field Methods, 17(1), 3-29. https://doi.org/10.1177/1525822X04272452

Heberlein, T. A., \& Baumgartner, R. (1978). Factors affecting response rates to mailed questionnaires: A quantitative analysis of the published literature. American Sociological Review, 43(4), 447-462. https://doi.org/10.2307/2094771

Helgeson, J. G., Voss, K. E., \& Terpening, W. D. (2002). Determinants of mail-survey response: Survey design factors and respondent factors. Psychology \& Marketing, 19(3), 303-328. https://doi.org/10.1002/mar.1054

Johnson, T. P., O'Rourke, D., Burris, J., \& Owens, L. (2002). Culture and survey nonresponse. Survey Nonresponse, 55-69.

Keeter, S., Miller, C., Kohut, A., Groves, R. M., \& Presser, S. (2000). Consequences of reducing nonresponse in a national telephone survey. Public Opinion Quarterly, 64(2), 125-148. https://doi.org/10.1086/317759

Lugtig, P. (2014). Panel attrition separating stayers, fast attriters, gradual attriters, and lurkers. Sociological Methods \& Research, 43(4), 699-723. https://doi.org/10.1177/0049124113520305

Pääkkönen, H. (1998). Are busy people under- or over-represented in national time budget surveys? Loisir et Société / Society and Leisure, 21(2), 573-582. https://doi.org/10.1080/07053436.1998.10753672

Peytchev, A. (2013). Consequences of survey nonresponse. The ANNALS of the American Academy of Political and Social Science, 645(1), 88-111. https://doi.org/10.1177/0002716212461748

Qvist, H. P. (2014). Ikke-vestlige indvandreres frivillige arbejde. In L. S. Henriksen \& T. Fridberg (Eds.), Udviklingen i frivilligt arbejde 2004-2012 (Vol. 14:09, pp. 161 181). Copenhagen: SFI. 
Ryu, E., Couper, M. P., \& Marans, R. W. (2006). Survey incentives: Cash vs. in-kind; face-to-face vs. mail; response rate vs. nonresponse error. International Journal of Public Opinion Research, 18(1), 89-106. https://doi.org/10.1093/ijpor/edh089

Sax, L. J., Gilmartin, S. K., \& Bryant, A. N. (2003). Assessing response rates and nonresponse bias in web and paper surveys. Research in Higher Education, 44(4), 409-432. https://doi.org/10.1023/A:1024232915870

Schoeni, R. F., Stafford, F., Mcgonagle, K. A., \& Andreski, P. (2013). Response rates in national panel surveys. The ANNALS of the American Academy of Political and Social Science, 645(1), 60-87. https://doi.org/10.1177/0002716212456363

Sharp, L. M., \& Frankel, J. (1983). Respondent burden: A test of some common assumptions. Public Opinion Quarterly, 47(1), 36. https://doi.org/10.1086/268765

Sheehan, K. B., \& McMillan, S. J. (1999). Response variation in e-mail surveys: An exploration. Journal of Advertising Research, 39(4), 45-54.

Tourangeau, R. (2003). Cognitive aspects of survey measurement and mismeasurement. International Journal of Public Opinion Research, 15(1), 3-7. https://doi.org/10.1093/ijpor/15.1.3

Uhrig, S. C. (2008). The nature and causes of attrition in the British household panel study. ISER Working Paper Series. Retrieved from: http://www.econstor.eu/handle/10419/92025

van Ingen, E., Stoop, I., \& Breedveld, K. (2009). Nonresponse in the Dutch time use survey: Strategies for response enhancement and bias reduction. Field Methods, 21(1), 69-90. https://doi.org/10.1177/1525822X08323099

Voogt, R. J. J., \& Saris, W. E. (2003). To participate or not to participate: The link between survey participation, electoral participation, and political interest. Political Analysis, 11(2), 164-179. https://doi.org/10.1093/pan/mpg003 